\title{
MÓNADAS Y COMPUESTOS
}

\author{
MARIA RAMON CUBELLS BARTOLOMÉ \\ UNIVERSITAT ROVIRA I VIRGILI \\ (TARRAGONA).
}

\section{INTRODUCCIÓN: UNA CORRESPONDENCIA MALTRATADA.}

Frente al habitual esfuerzo hermenéutico que la mayor parte de obras de Leibniz ha motivado, la Correspondencia mantenida por el filósofo con Des Bosses (iniciada el año 1706 y finalizada el 1716, el mismo año que murió Leibniz) no ha sido una obra bien acogida por la crítica. Aunque este Epistolario es conocido y hasta utilizado para encontrar aquellas palabras del filósofo que interesan a un posible crítico para refrendar su "visión" del "corpus" leibniziano, muy pocos comentaristas han hecho un estudio minucioso de la discusión que mantienen los corresponsales en estos diez años de cartas. La causa de este tratamiento no es sólo un fácil acomodamiento a la tesis russelliana que colocaría esta Correspondencia dentro de las obras "flojas" de Leibniz, sino un hecho que ha facilitado la rápida clasificación de las cartas. Éste es que en el Epistolario del filósofo luterano con el

1 Este panorama general debe ser matizado indicando, al menos, las obras dedicadas al estudio (parcial o global) de las cartas:

BLONDEL, M. De Vinculo substantiale et de Substantia composita apud Leibnitium. Alcan. Lutetiae Parisiorum, 1893. (Hay una edición a cargo de C. Troisfontaines con el texto en latín y la traducció francesa, en Nauwelaerts, Paris, 1972.). También de BLONDEL, Un énigme historique. Le "Vinculum substantiale" d'après Leibniz et l'ébauche d'un réalisme superieur.Beauchesne. Paris, 1930.

BOEHM, A. Le "Vinculum Substantiale" chez Leibniz. Ses origenes historiques. Vrin. Paris, 1962. (Primera edición:1938)

MATHIEU, V. Leibniz $e$ Des Bosses. Giappichelli. Torino, 1960.

Por su parte CH.FREMONT presenta un estudio preliminar a la traducción de algunas de las cartas de Leibniz a Des Bosses, en: $L$ 'être et la relation (avec Trente-cinq Lettres de Leibniz au R.P. Des Bosses). Vrin. Paris, 1981.

Éndoxa: Series Filosరficas, $n^{\circ} 4,1994$, UNED, Madrid:

María Ramón Cubells: Mónadas y compuestos.

pp. 129-136. 
jesuita Des Bosses se discute el misterio católico de la Transubstanciación. La presencia de este "tema" ha permitido a muchos críticos concluir que no puede haber nada interesante en semejante intercambio epistolar y que el objetivo de tantas páginas escritas es, solamente, el deseo de Leibniz de agradar a los católicos o, concretamente, a la Compañía de Jesús.

Otro motivo de desconfianza frente a las cartas, no desligado del primero, es la aparición en ellas de un elemento "extraño" o, mejor, de una teoría singular, que sólo aquí Leibniz se permite mostrar: la del Vinculum Substantiale. Pero, en muchos casos no se trata de un rechazo porque en el sistema monadológico no quepa el Vínculo y, por lo tanto, resulte incoherente admitirlo, sino porque se piensa la teoría como la solución a un problema que no se ha admitido como auténtico problema leibniziano, es decir: se cree que es una solución para explicar aquel dogma católico.

Si dejamos de lado estos prejuicios (en lo que de ello tienen ciertas interpretaciones) y leemos con atención la Correspondencia, dos cosas destacan inmediatamente: la Transubstanciación no es un "tema" del Epistolario y, evidentemente, el papel fundamental del Vínculo Substancial no es permitir explicarla dentro de los márgenes de la filosofía leibniziana. Claro está que aparece la temática eucarística en las cartas de ambos corresponsales, sin embargo tiene el rol de ejemplo, su función es permitir ensayar la concebibilidad de las "substancias compuestas", y ésta es también la razón por la cual Leibniz presenta la teoría del Vínculo.

Consideramos, utilizando la expresión de M. Blondel ${ }^{2}$, que sólo por "razones intrínsecas" al leibnizianismo nos está permitido dudar del valor de la solución (el Vinculum) al problema de la substancialidad del compuesto y no, en cambio, por motivos

M. BLONDEL en De Vinculo substantiale et de Substantia composita apud Leibnitium, Cap.1. 
ajenos a éste, como la posible insinceridad del filósofo discutiendo con Des Bosses o la mala fe de Leibniz permitiendo un debate de diez años que no tuviera para él ningún sentido.

2. PLANTEAMIENTO DE LA CUESTIÓN DESDE UNA VALORACIÓN DE LA CORRESPONDENCIA.

Como acabamos de apuntar, el elemento clave alrededor del cual gira toda la discusión que encontramos en el Epistolario, es la Substancia Compuesta. ¿Que queremos decir con ello? Simplemente que en estas cartas Leibniz se plantea la posibilidad de substancializar algunos compuestos. Desde nuestro punto de vista, ello significa que estamos dentro de una discusión genuinamente leibniziana, la relativa a la "substancia", tema clave que preocupó al filósofo durante toda su trayectoria intelectual.

El punto de partida de Leibniz no es diferente aquí al de otros de sus textos: la definición de la substancia o mónada que incluye las notas distintivas siguientes: simplicidad, inmaterialidad y fuerza. Nos encontramos en el sistema de aquellas mónadas que no tienen ni puertas ni ventanas (que no tienen relaciones externas), porque resultan innecesarias al estar pensadas desde la completud más absoluta. La mónada se concibe desde el movimiento expresivo, su "discurrir" en el tiempo está sometido a un movimiento de desenvolvimiento o de envolvimiento, porque todo permanece siempre lo mismo con distintos grados de expresión, esto es: de mostración o de ocultamiento; se trata de explicitar aquello que ya está contenido en el propio fondo o de mantenerlo cerrado e implícito. Si todo está tan claro, ¿por qué aparece el problema de otorgar substancialidad a los compuestos? Porque a pesar de Descartes, la substancialidad del propio sujeto entendiéndolo como compuesto, le pareció al filósofo que merecía nuevas meditaciones.

Leibniz, oponiéndose a la consideración de la extensiónsubstancia de los cartesianos, trata de nuevo la cuestión de la unidad del compuesto (orgánico). Inicialmente, motivado por la 
primera demanda de Des Bosses, no duda en responder desde la tesis de las mónadas solas (y de la armonía), entendiendo que aquello que no es substancia es fenómeno. Pero el jesuita problematiza la respuesta del filósofo hasta que éste ensaya una nueva posibilidad: la substancia compuesta. Precisamente, a nuestro entender, la importancia de la Correspondencia yace ahí: en el esfuerzo de Leibniz para pensar al organismo como siendo algo más que un agregado, en el trabajo de pensar la hipótesis de las substancias compuestas. La discusión que mantendrá durante los últimos años de su vida, no es más que sobre la concebibilidad de la substancia compuesta. No es que el filósofo la afirme sin más, siempre encontramos su respuesta formulada desde el condicional: "Si hay substancias compuestas, ...". Leibniz quiere posibilitarlas desde sus referencias, desde el propio marco sistemático. El alcance de la cuestión se aclara cuando nos percatamos de que estamos ante un modo de pensar enfrentado con un problema del que no puede evadirse, pero, como hemos querido mostrar en otro lugar ${ }^{3}$, para el que tampoco tiene soluciones coherentes con muchos de sus presupuestos filosóficos.

\section{EL PROBLEMA: LA SUBSTANCIA COMPUESTA.}

Antes de volver a la cuestión planteada en las cartas que nos ocupan, debemos señalar un hecho que no parece baladi, nos referimos al distinto tratamiento (por lo menos "nominal") que esta temática tiene en dos obras del filósofo escritas ambas en 1714, la Monadología y los Principios de la Naturaleza y la Gracia. Así, mientras en la segunda de estas obras Leibniz utiliza la expresión "substancias compuestas", en la Monadología nunca utiliza esta terminología, en su lugar generalmente encontramos "compuestos", y además parece que se haya procurado evitarla conscientemente. Por otra parte, también debemos constatarlo, si se exceptúa la

3 La Correspondència entre Leibniz $i$ Des Bosses (1706-1716). Tesis doctoral. Universitat de Barcelona, Abril, 1993. 
Correspondencia con Des Bosses, en los textos posteriores a 1686 (particularmente el Discurso de Metafísica, la Correspondencia con Arnauld y las cartas a Rémond), aunque lo más destacable sea la gran vacilación de Leibniz a la hora de decidir si afirma o niega la substancialidad de algunos compuestos, encontramos que la respuesta afirmativa pasa por la necesidad de la Forma Substancial, en el sentido que ella es la encargada de "hacer" la unificación que posibilite las substancias compuestas. Lo interesante desde esta perspectiva (quizás ahora un poco restrictiva) es que en el Epistolario con Des Bosses, Leibniz analizará con más atención esta propuesta, y ello le conducirá al rechazo de esa solución (la forma substancial) por parecerle insatisfactoria y será entonces cuando ligará la hipótesis de las substancias compuestas con la teoría del Vínculo Substancial.

Desde ese momento nos cercioramos de que el Vínculo aparece para posibilitar la hipótesis de la Substancia Compuesta y no porque surjan problemas teológicos. De todas maneras, volvamos a la cuestión antes planteada, ¿por qué una nueva hipótesis? Como todo lector de Leibniz sabe, en el sistema la substancialidad sólo conviene a lo simple (mónada) y la entidad de los compuestos es fenoménica. Para que algo sea "fenómeno" es necesario un sujeto percipiente, ya que éste le confiere "realidad" (total o parcial) en tanto que es un contenido objetivo (representativo) de este sujeto. En el ámbito ontológico, no hay más unidad (entidad) que la de la substancia, unum per se, el resto son unificaciones no esenciales (unum per accidens), que se designan con la noción de agregado. Desde aquí, si el término substancia sólo es adecuado a lo simple, decir "substancia compuesta" es no decir nada o es un sin sentido. Pero aquello que Leibniz ahora parece querer evitar es la indistinción entre lo orgánico y lo inorgánico, que se produciría si ambos son agregados (aunque se permita una diferencia de grado), es decir si son categorias del mundo de la apariencia. Así, pues, en el largo diálogo con Des Bosses, Leibniz quiere pensar y formular la diferencia ontológica de un tipo de agregación, las unidades orgánicas, respecto del resto; la diferencia, pues, entre el pez y el 
estanque, la oveja y el rebaño, el soldado y el ejército. Diferencia que, por cierto, no queda aclarada desde la armonía preestablecida, porque se desvirtúa el tipo de unidad (en sí) que nos permite decir de un ser vivo (orgánico) que es real más allá de la realidad de la representación (desde la cual también la sirena y el centauro son reales).

Adentrándonos en los resultados de la reflexión del filósofo en aquellas cartas, Leibniz expone la necesidad de un elemento nuevo que permita aquella unificación que no consigue desde las mónadas. Por ello, si además de éstas hay un vínculo substancial, parece factible algo más que la automática agregación: permite ligar (realmente) la mónada y la materialidad (corporeidad), posibilita introducir, y ahora con sentido, la expresión "substancias compuestas". Este vínculo es substancial porque no agrega sino que "une", permite hablar de unum per se, deja pensar la diferencia que intuitivamente ponemos entre el ejército y el solado. Si recurrir a la "mónada dominante" (en otros textos Leibniz prefirió la denominación de "forma dominante" o "forma substancial") se considera ahora insuficiente es porque la relación dominaciónsubordinación no permite concebir a esa mónada dominante como esencialmente distinta de las otras (subordinadas), es decir el ser mónada le impide ejercer la función que antes el filósofo le había encomendado: unificar esencialmente lo compuesto, convirtiendo un agregado en substancia (compuesta). En este punto, Des Bosses se mostrará muy en desacuerdo con el filósofo, porque desde su perspectiva la Mónada Dominante es suficiente, pero es que el corresponsal la piensa como parte esencial de una substancia compuesta completa (por lo que no necesita de vínculo substancial alguno), para Des Bosses no es nada diferente a la Forma aristotélica. Como sabemos, Leibniz considera entonces que el amigo jesuita ha sacrificado la completud que caracteriza a la mónada, que dejaría consecuentemente de ser substancia. Mientras para Des Bosses sólo el compuesto es substancia completa, para Leibniz la completitud de la mónada es intocable. 
El Vínculo es propuesto precisamente porque parece respetar la constitución de la mónada. Si intentamos caracterizarlo (sin olvidar que se trata de una teoría más ensayada que acabada) la primera cosa que debemos señalar es que el Vinculum substantiale es algo que se añade, en el sentido de que se superpone (supperadditum) a un conjunto de elementos para hacer una composición (real). Este vínculo no está en el lado de los fenómenos, no tiene "realidad" física (fenoménica) sino metafísica (objetiva), pero tampoco es una representación.

Lo interesante es que este elemento no es algo que contienen las mónadas (por eso no es una representación y por ello es sobreañadido), pero tampoco es algo que forma parte del compuesto (del agregado). El Vinculum es un "elemento" "nuevo": no es un modo de las mónadas porque para Leibniz la modalidad (toda accidentalidad) es fenoménica $y$, desde aquí, no podría dar cuenta de la substancia compuesta; es decir, si fuera un fenómeno no podría ejercer como substancializador. Evidentemente, tampoco debe ser pensado como una especie de gancho físico (material), porque entonces sería otra parte (un elemento más) del compuesto. Pero, aunque Leibniz diga, en un momento de la Correspondencia, que es una relación, no lo caracteriza como tal, sencillamente porque tampoco entonces podría hacer una substancia (sería un fenómeno añadido a otro).

El Vínculo Substancial es aquello que une, es el "uniente", pero no es (a pesar de ciertas vacilaciones del filósofo) la substancia compuesta, ya que ésta es el resultado de aquello que el vínculo posibilita. No obstante el Vínculo no une mónadas (como si se tratará de partes del compuesto), puesto que ellas nunca son pensadas como ingredientes de una composición, y en este sentido también sería incorrecto, al fin y al cabo, hablar de agregación de mónadas (porque el agregado es también algo meramente físico). Aquello que es parte es físico (en el sistema) y, por lo tanto, el Vínculo proporciona verdadera unidad a un conjunto de piezas que hacen un organismo, es decir un ser vivo que deviene 
substancia siendo compuesto. Pero ¿es ésta la misión que se le había encomendado?

Aunque ahora no podamos mostrar el alcance de la cuestión, algo ya se ha insinuado; es preciso añadir que las cartas de Leibniz a Des Bosses evidencian una tensión más fundamental, que el Vínculo debía solucionar. Se trata de la re-unión de ámbitos (el monádico o metafísico y el material o físico), de procurar un pasillo entre niveles abismalmente separados. La hipótesis del Vínculo (o el intento de construirla) si bien se nos presenta como una posibilidad para pensar el organismo y, por tanto de re-pensar la unión entre cuerpo y alma, no tiene éxito porque el hiato entre aquella vida representativa (alma) y aquella física (cuerpo), no es tapado más que de forma nominal, porque la mediación entre estas dos esferas es imposible, en definitiva, porque el Vinculum no puede ligar y unir la mónada y la materia. 